\title{
Determination of Critical Separation Distance Between Dwellings in Informal Settlements Fire
}

\author{
Yu Wang (D*, BRE Center for Fire Safety Engineering, School of Engineering, \\ University of Edinburgh, Edinburgh EH9 3JL, UK and State Key \\ Laboratory of Fire Science, University of Science and Technology of China, \\ Hefei 230026, PR China \\ Lesley Gibson, Mohamed Beshir and David Rush*, BRE Center for Fire Safety \\ Engineering, School of Engineering, University of Edinburgh, Edinburgh \\ EH9 3JL, UK
}

Received: 7 May 2020/Accepted: 23 November 2020

\begin{abstract}
Approximately one billion people across the globe are living in informal settlements with a large potential fire risk. Due to the high dwelling density, a single informal settlement dwelling fire may result in a very serious fire disaster leaving thousands of people homeless. In this work, a simple physics-based theoretical model was employed to assess the critical fire separation distance between dwellings. The heat flux and ejected flame length were obtained from a full-scale dwelling tests with ISO 9705 dimension $(3.6 \mathrm{~m} \times 2.4 \mathrm{~m} \times 2.4 \mathrm{~m})$ to estimate the radiation decay coefficient of the radiation heat flux away from the open door. The ignition potential of combustible materials in adjacent dwellings are analyzed based on the critical heat flux from cone calorimeter tests. To verify the critical distance in real informal settlement fire, a parallel method using aerial photography within geographic information systems (GIS), was employed to determine the critical separation distances in four real informal settlement fires of 2014-2015 in Masiphumelele, Cape Town, South Africa. The fire-spread distances were obtained as well through the real fires. The probabilistic analysis was conducted by Weibull distribution and logistic regression, and the corresponding separation distances were given with different fire spread probabilities. From the experiments with the assumption of no interventions and open doors and windows, it was established that the heat flux would decay from around $36 \mathrm{~kW} / \mathrm{m}^{2}$ within a distance of $1.0 \mathrm{~m}$ to a value smaller than $5 \mathrm{~kW} / \mathrm{m}^{2}$ at a distance of $4.0 \mathrm{~m}$. Both experiments and GIS results agree well and suggest the ignition probabilities at distances of $1.0 \mathrm{~m}, 2.0 \mathrm{~m}$ and $3.0 \mathrm{~m}$ are $97 \%, 52 \%$ and $5 \%$ respectively. While wind is not explicitly considered in the work, it is implicit within the GIS analyses of fire spread risk, therefore, it is reasonable to say that there is a relatively low fire spread risk at distances greater than $3 \mathrm{~m}$. The distance of $1.0 \mathrm{~m}$ in GIS is verified to well and conservatively predict the fire spread risk in the informal settlements.
\end{abstract}

\footnotetext{
*Correspondence should be addressed to: Yu Wang, E-mail: yuwang@ustc.edu.cn; David Rush, E-mail: D.Rush@ed.ac.uk
} 
Keywords: Informal settlements, Fire spread, Full scale, Critical separation distance, GIS

\section{Introduction}

Increasing poverty continues to characterise urban conditions, particularly in the Global South [1], which in turn poses sustainability and disaster risk reduction challenges. It is now estimated that approximately one billion people across the globe live in informal dwelling settlements, and this number is ever increasing (from 650 million to 862 million between 1990 and 2012) [2]. Many of these informal settlements (i.e. shantytowns, favelas, slums) are at constant risk of lethal, large-scale destructive fires due to flammable construction materials, potentially dangerous heating and cooking methods, dwelling proximity, etc. This potential fire risk is particularly high in developing regions including Sub-Saharan Africa, Southern Asia and South America. For example, across South Africa, there are an estimated ten informal settlement dwelling fires a day, often leaving residents dead and thousands more homeless. In Cape Town alone, there are around 500 deaths and 15,000 fire-related hospital admissions due to fire annually, of which a substantial proportion are people from informal settlements [3].

However, with local populations lacking in resources and opportunity to build more robust homes, materials that are easily obtainable, including cardboard, paper, wood, galvanized steel sheeting and plastic, are often used in construction of an informal settlement dwelling [4]. Housing rarely complies with current planning and building regulations, and is often situated in geographically and environmentally hazardous areas [5]. Fires can spread very quickly in informal settlements with multiple households in a community potentially losing their homes, eroding community resilience to disaster as social support networks are disrupted in a single event $[6,7]$. What is more, building dimension, building-to-building separation and construction methods, which are very complicated in informal settlement, will significantly affect the fire spread rate. Thus, it becomes very difficult to prevent and predict the fire spread between the dwellings in informal settlements.

Some measures, including improved cooking stoves, electrification of areas, fire retardant paint, smoke alarms, and heat detectors, are being trialled by local fire rescue services or government departments [8]. However, research is still ongoing to quantify what, if any, impact they have in reducing fire deaths and injuries in real fire events $[8,9]$. In addition, the social impact of these fire protection method on the local residents is complex and may be beyond the settlement protection technology itself [10]. Until now there has been no efficient way to deal with such a complicated fire safety situation.

It has long been recognised that the risk of fire spreading from one building to another reduces as the distance between them increases [11, 12]. Larger separation distances may also be critical for the ignition for liquid fuel fire [13] and CNG filling station [14]. More recently, BR 187-External Fire Spread, Building Separation and Boundary Distances [15] has been the main reference for determining the required building separations in the UK, and similar requirements are included in for example NFPA 80A [16]. From a previous case study in South Africa, it is 
generally accepted that in informal settlements increasing the separation distance between dwellings or blocks of dwellings in process of 'reblocking' a settlement is anticipated to reduce the risk of fire spread [6]. Local residents are prone to construct dwellings close together due to competition for the limited land in such settlements, thus the balance between the dense living conditions and fire safety needs to be carefully considered, particularly as the implementation of fire safety codes and regulations is extremely hard in these areas. Very limited research has focused on the critical separation fire safe distance for informal settlements, except some research on earthquake transitional resettlement [17, 18]. Preliminary theoretical analyses were performed by the authors [19], however more reliable experimental and theoretical results are needed to confirm the initial study's conclusions.

In this work, ejected flame impingement and radiation from dwelling openings will be investigated due to their critical role in determining the critical fire separation distance between informal dwellings [18]. The heat flux at different distances from the door during the full-scale experiments are obtained and a simple physicsbased theoretical model is used to estimate the results. The critical heat fluxes (CHF) of informal settlement materials from a series of cone calorimeter tests are employed to determine if the combustible construction in the adjacent dwelling will be ignited. For comparison and verification, a completely different method using very high resolution aerial images is employed in parallel to the experimental and analytical analyses. Four large informal settlement fires which occurred in Masiphumelele, Cape Town, South Africa, between May 2014 and November 2015 were mapped using imagery obtained from the City of Cape Town Open Data Portal, as shown in Fig. 1. These fires caused serious losses. For example,

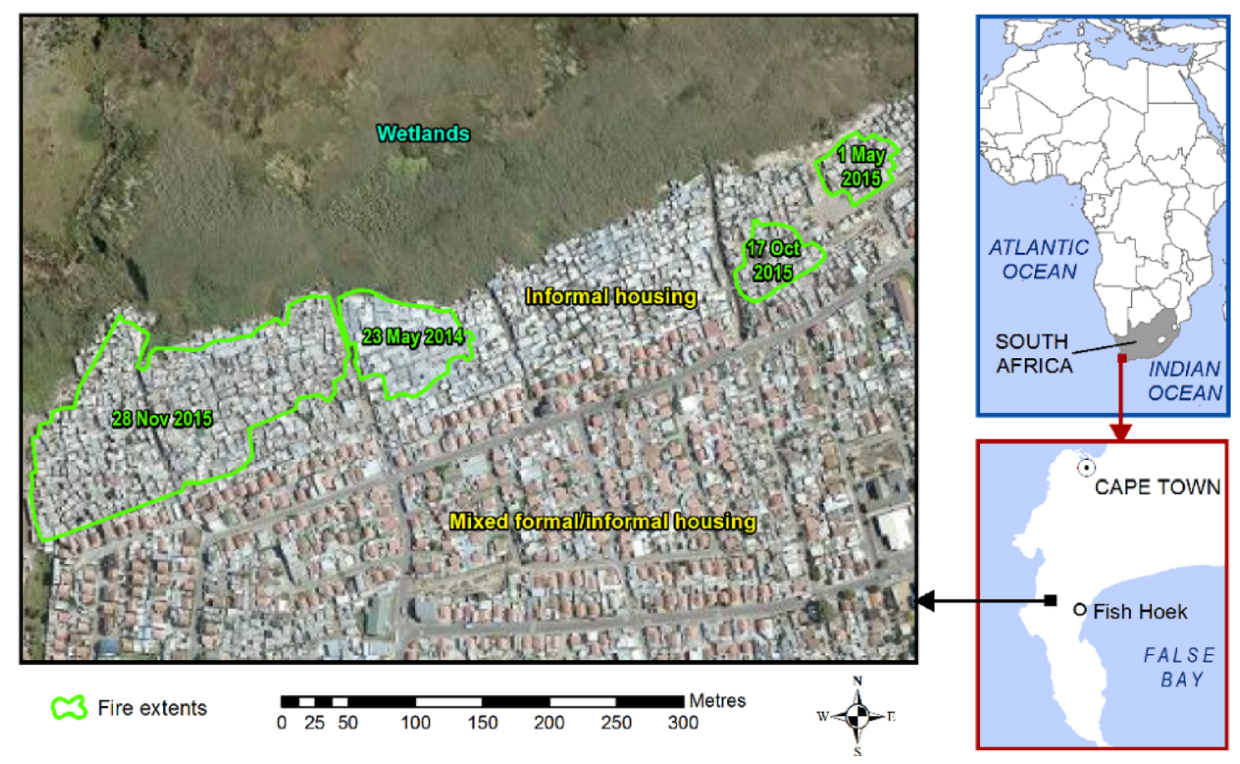

Figure 1. Location of the Masiphumelele settlement showing the sites of fires. 
the November 2015 fire left 2 dead and 4000 homeless and the May 2014 fire left 1000 people homeless. High-resolution aerial photography in a geographic information system (GIS) is used to determine the dwelling offset distances of the four fires that occurred in Masiphumelele, and the distances where the fire did and did not spread are obtained. The theoretical heat flux distance results are compared with the GIS measured distances to determine the conservative separation distance between dwellings in the informal settlements.

\section{Analysis of Experiments}

\subsection{Experimental Conditions}

Both full-scale experiments and cone calorimeter tests were conducted for this critical distance evaluation. It should be noted that a series of 13 full-scale experiments were conducted at Underwriters Laboratories (UL), Chicago, IL, of which a small portion of useful data is used in this work. The specific description of the experimental condition and measurement instruments can be found in [20] and more detailed data will be shown in our future work. For the full-scale experiment used in this work, a single compartment was constructed with galvanized steel sheeting walls connected to timber frames. The dimensions of the compartment are determined according to the ISO 9705 that is $2.4 \mathrm{~m}$ (height) $\times 3.6 \mathrm{~m}$ (length) $\times 2.4 \mathrm{~m}$ (width) [21], with a door of dimension of $2.0 \mathrm{~m}$ (height) $\times 0.8 \mathrm{~m}$ (width) and window of $0.6 \mathrm{~m}$ (height) $\times 1.2 \mathrm{~m}$ (width), as shown in Fig. 2a. Two wood cribs were placed at the centre of the compartment and each crib consists of 7 layers of 10 sticks with a dimension of $0.038 \times 0.064 \times 1.219 \mathrm{~m}^{3}$. Thus, the fuel load of the compartment is $25.0 \mathrm{~kg} / \mathrm{m}^{2}$. Two water-cooled heat flux gauges, with $\mathrm{K}$ type $1 \mathrm{~mm}$ diameter thermocouples, were respectively fixed at 2.0 and $3.0 \mathrm{~m}$ away from the centreline of the door at a height of $1.60 \mathrm{~m}$, as shown in Fig. 2a. Six thermocouples, with the heights of $0.40,0.80,1.05,1.30,1.55$ and $1.80 \mathrm{~m}$, were placed at the centreline of the door; one placed at $1.55 \mathrm{~m}$ height in the door (almost $1.6 \mathrm{~m}$ ) will be used for comparison. The ambient temperature inside the experimental hall on the test day was approximately $13^{\circ} \mathrm{C}$.

This experimental design reflects the average fuel load and construction method in real informal settlements $[8,20]$. In particular, the wall is thermally thin metal which is very different from formal dwellings but similar to informal settlement dwellings. From a large household survey commissioned by the authors, which included hundreds of dwellings, it was established that the shapes of the dwellings range from rectangle to $L, T, Z$ and $U$. Overall, the rectangle shape accounts for around $60 \%, L$ around $20 \%, Z$ around $8 \%, T$ around $5 \%$. Thus, it is difficult to determine a typical set of dimensions, however, it was found that the lengths are primarily in the range of $2 \mathrm{~m}$ to $6 \mathrm{~m}$ and the heights are primarily in the range of $1.9 \mathrm{~m}$ to $2.5 \mathrm{~m}$ (for one floor dwelling). The ISO 9705 dimensions are thus selected so that the results can be compared to previous research to deepen the understanding of the effect of boundary conditions on informal settlement dwelling fires. 


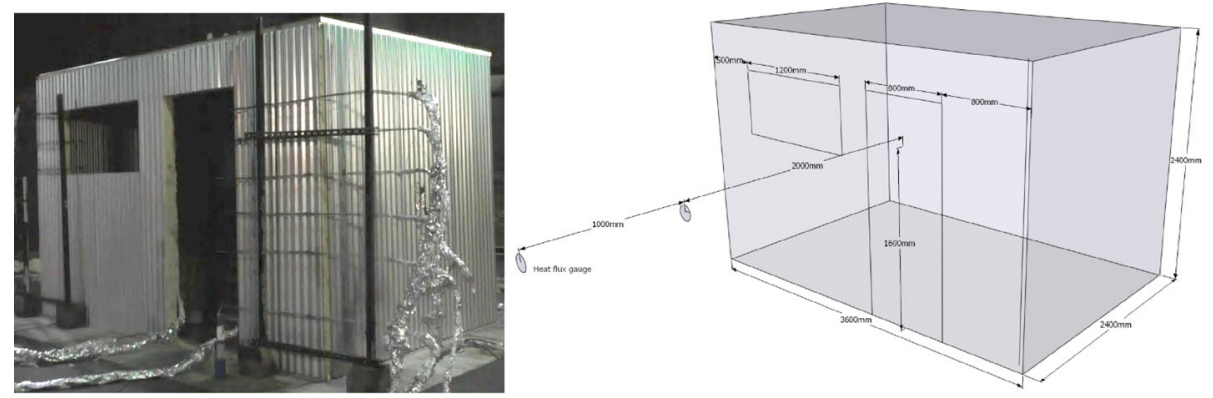

(a) The compartment with ISO 9705 dimension

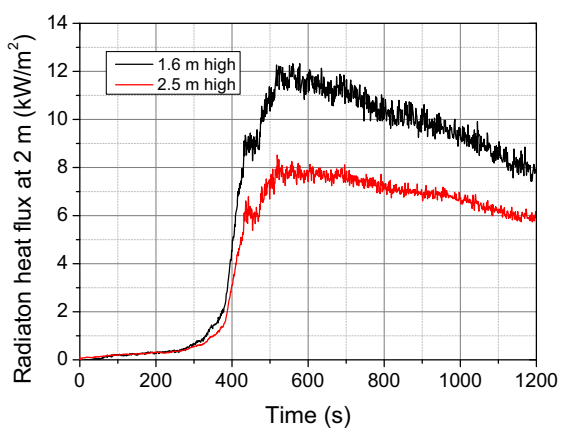

(b) The heat flux at different heights

\section{Figure 2. The compartment and the arrangement of the heat flux gauges.}

From the initial experiments conducted at UL, it was found the heat fluxes (measured using thin skin calorimeters) at the same distance away from the window and door were very similar when they are both located in the same wall (as shown in Fig. 2a below), which is consistent with a numerical prediction in previous work [22]. Thus, only the door heat fluxes were measured by water cooled gauges in the presented experiment. The height of measurement was also assessed from another full-scale test with identical compartment and door size in our series of full-scale experiments by water-cooled heat flux gauges, where the heat flux at a height of

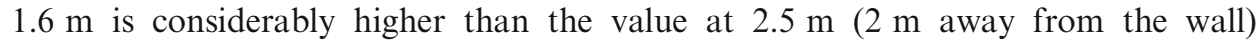
despite the ejected plume above the door, as shown in Fig. 2b. The experiment in this work is thus considered as a conservative case of informal settlement dwelling with a door and a window on the same wall, which would result in a relatively large heat flux in front of the openings. This experiment was conducted under a large fire calorimeter hood $(7.62 \mathrm{~m}$ off the floor, $7.62 \mathrm{~m}$ diameter hood inlet) in Underwriters Laboratories with the measurement of heat release rate (HRR).

With the radiation heat flux from the full-scale experiments, a series of cone calorimeter tests were performed to determine the critical heat flux for ignition of the combustible materials commonly found in informal settlements as per ISO 
5660 [23]. All combustible materials were collected from an informal settlement near Worcester, South Africa. A total of 32 different materials were tested, as shown in Table 1. The samples were exposed to an external heat flux until sustained flaming ignition occurred or until no ignition had occurred within $1200 \mathrm{~s}$ of exposure. More information about the cone tests results can be found in the authors' another work in which a database about the burning characteristic of these combustible materials in the informal settlement has been created [4]. It should be noted that, due to the very different properties, the ignition definition was unified for all the tests: the specimen was considered as ignited after sustained flaming for $4 \mathrm{~s}$ in each test [24]. Smouldering, glowing or flash were not consid-

\section{Table 1}

The Material List for the Cone Calorimeter Tests [4]

\begin{tabular}{|c|c|c|c|c|}
\hline No. & $\begin{array}{l}\text { Material } \\
\text { type }\end{array}$ & Specific material & $\begin{array}{l}\text { Thickness } \\
(\mathrm{mm})\end{array}$ & Note \\
\hline 1 & Timber & Structure timber & 36 & Most common, pine \\
\hline 2 & & Fuel timber & 50 & Fuel, saligna \\
\hline 3 & & Masonite timber & 3 & $\begin{array}{l}\text { Masonite board, commonly used in furniture, } \\
\text { on doors or lining homes }\end{array}$ \\
\hline 4 & & Timber furniture 1 & 16 & Chipboard-shelf section \\
\hline 5 & & Timber furniture 2 & 16 & Chipboard - cupboard section \\
\hline 6 & Plastic and & Plastic bag & $<1$ & Woven plastic bag \\
\hline 7 & rubber & Clear plastic sheet & $<1$ & Used as table cover \\
\hline 8 & & Shade netting & 1 & Plastic \\
\hline 9 & & Tyre & 6 & - \\
\hline 10 & Cardboard & Cardboard 1 & 5 & - \\
\hline 11 & & Cardboard 2 & 3 & - \\
\hline 12 & Newspapers & Normal paper & $<1$ & - \\
\hline 13 & & Advertisement & $<1$ & - \\
\hline 14 & Foam & Dark yellow foam & 50 & Polyurethane foam \\
\hline 15 & & Light yellow foam & 50 & Furniture foam \\
\hline 16 & & Pink foam & 19 & General packaging foam \\
\hline 17 & & $\begin{array}{l}\text { White polystyrene } \\
\text { foam }\end{array}$ & 19 & Packaging polystyrene \\
\hline 18 & & Big green insulation & 50 & Isotherm insulation, not common \\
\hline 19 & Bedding & Colourful blanket & 5 & Local cheap blanket, very common type \\
\hline 20 & & Pink blanket & 1 & Used on bed \\
\hline 21 & & Pillow cover & $<1$ & - \\
\hline 22 & Floor cov- & Red welcome carpet & $1+3$ & Welcome mat \\
\hline 23 & ering & Green carpet & $2+4$ & Old discarded carpet \\
\hline 24 & & Yellow carpet & $1+5$ & Typical carpet \\
\hline 25 & & Vinyl & $<1$ & Polyvinyl chloride \\
\hline 26 & Curtain & Shower curtain & $<1$ & - \\
\hline 27 & & $\begin{array}{l}\text { Yellow smooth win- } \\
\text { dow curtain }\end{array}$ & $<1$ & Thin drape curtain \\
\hline 28 & & Pink curtain & $<1$ & - \\
\hline 29 & Clothing & Blue T-shirt & $<1$ & - \\
\hline 30 & & Black trousers & $<1$ & - \\
\hline 31 & & Grey trousers & $<1$ & - \\
\hline 32 & & Women leggings & $<1$ & - \\
\hline
\end{tabular}


ered as ignition, as the visible flame and its radiation are considered more important to fire spread mechanisms in informal settlements.

\subsection{Results}

2.2.1. The Study Region The temperatures and radiation heat fluxes across the whole burning process are plotted in Fig. 3. From the temperature curves at $0.0 \mathrm{~m}$ (at the door) in Fig. 3a, it can be seen that flashover occurs at around $300 \mathrm{~s}$,

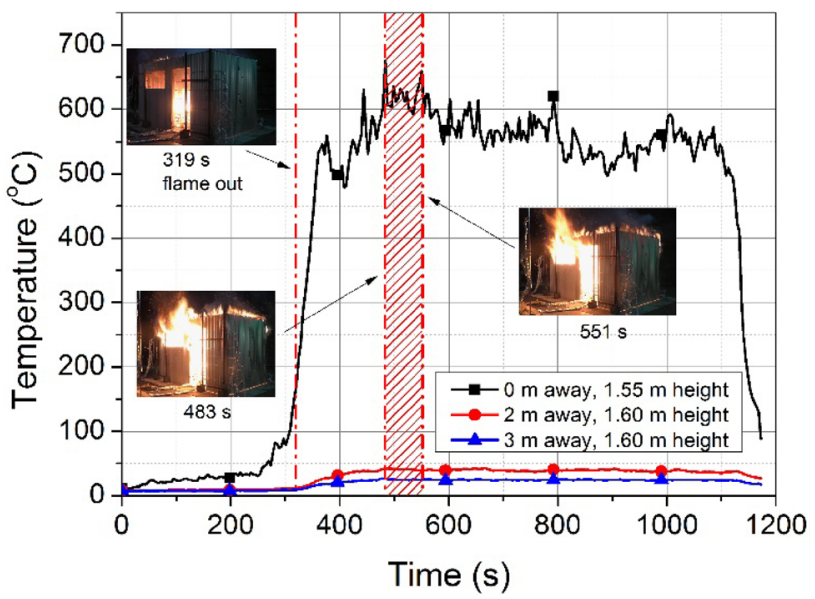

(a) The temperatures at different distances

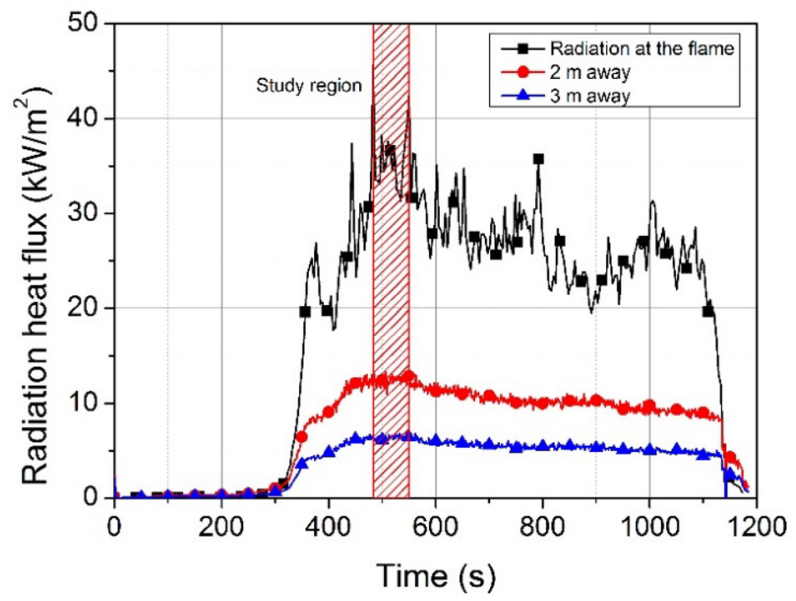

(b) The radiation heat flux at different locations

Figure 3. The temperatures and radiation heat flux at different locations. 
which can be confirmed by the video that the flame first appeared outside the compartment at $319 \mathrm{~s}$. In the post-flashover stage, the temperature remained stable in a relatively small range of $500^{\circ} \mathrm{C}$ to $650^{\circ} \mathrm{C}$. Meanwhile, the gas temperatures at 2.0 and $3.0 \mathrm{~m}$ away from the door were always below $43^{\circ} \mathrm{C}$, implying the heating at these locations came from radiation rather than convection. As for the heat flux, it was difficult to ensure the survival of a heat flux gauge engulfed in the flame to make an accurate measurement. Therefore, for simplicity, it is assumed that the flame temperature is constant through its full depth, namely the temperature drops sharply at the flame edge, which is considered conservative [25]. Thus, in this experiment, the flame tip temperature is assumed the same as the measured temperature at the door. Then the radiation heat flux received near the flame from the radiator (opening flame and room gas) can be estimated by [26] according to the opening dimension:

$$
I_{0}=I_{\text {flame }}+I_{\text {gas }}=\varepsilon_{\text {flame }} \sigma\left(T^{4}-T_{\mathrm{a}}^{4}\right)+\varepsilon_{\text {gas }} \sigma\left(T^{4}-T_{\mathrm{a}}^{4}\right)
$$

If there is no through draft:

$$
\begin{aligned}
\varepsilon_{\text {flame }} & =1-e^{-0.3 \times \frac{2}{3} h_{d}} \\
\varepsilon_{\text {gas }} & =1
\end{aligned}
$$

where $\sigma$ is Stefan-Boltzmann constant; $\varepsilon$ is emissivity; $T\left({ }^{\circ} \mathrm{C}\right)$ is the flame and room gas temperature; $T_{\mathrm{a}}\left({ }^{\circ} \mathrm{C}\right)$ is the ambient temperature which was $10^{\circ} \mathrm{C} ; h_{d}$ is the height of door that was $2.0 \mathrm{~m}$. The calculated (at the flame) and measured (2 and $3 \mathrm{~m}$ away) radiation heat fluxes are shown in Fig. $3 \mathrm{~b}$.

In addition, the temperature, heat flux and videos all clearly suggest the ejected flame became significantly larger from $483 \mathrm{~s}$ to $551 \mathrm{~s}$, with the largest energy release from the burning compartment and thus the highest probability to ignite adjacent dwellings. The collapse of a dwelling also poses a fire spread risk, but in

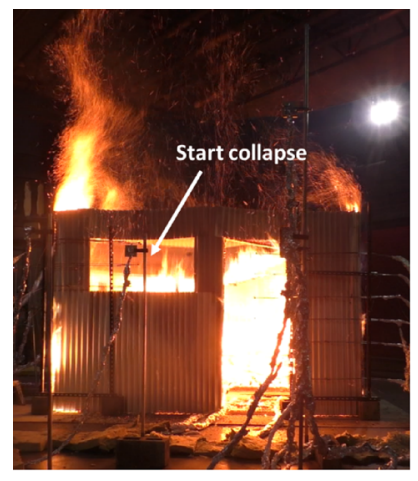

(a) $1131 \mathrm{~s}$

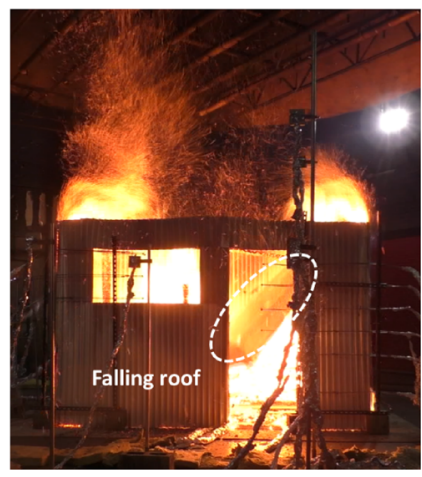

(b) $1132 \mathrm{~s}$

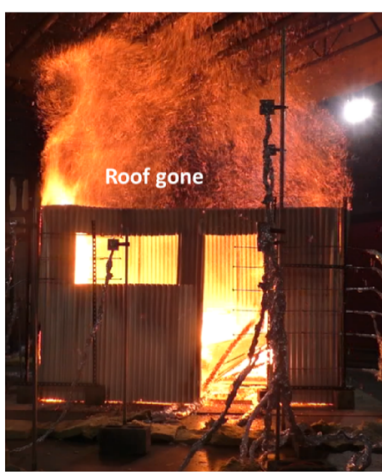

(c) $1133 \mathrm{~s}$ 
this experiment, the occurrence of roof collapse, as shown in Fig. 4, did not increase the heat flux measurement. Thus, the time range with the highest probability of fire spread is selected as the study region, as highlighted red in Fig. 3.

2.2.2. The Prediction of the Critical Distance Most informal settlement dwellings in and around Cape Town are single storey, very close to each other. Thus, only the flame spread in the horizontal direction is investigated in this work.

The flame length is first determined. Due to a large number of combustible materials in an informal settlement, it is assumed that the adjacent dwelling will be directly ignited when the projected flame length is beyond the distance between dwellings $[26,27]$. In the study region, the flame length is estimated from the video captured from the side of the wall. Only the visible flame is considered and scaled to the real length by the known dimension in videos. The interval is set as $1.0 \mathrm{~s}$ and then 68 flame lengths are measured, which vary from $0.58 \mathrm{~m}$ to $1.0 \mathrm{~m}$, with an average of $0.75 \mathrm{~m}$ and standard deviation of $0.09 \mathrm{~m}$, as shown in Fig. 5. Thus, a separation distances of below $0.75 \mathrm{~m}$ from an opening will almost certainly cause secondary structures to be ignited due to direct flame impingement.

In addition to the experimental observations, a physical-based method is used to predict flame length. The wall above the opening may determine the ejected plume shape which results in a different calculation method of flame length. To determine if there is a wall above the window, the flame height $z(\mathrm{~m})$ is calculated [25]:

$$
z=12.8\left(\frac{R}{w}\right)^{2 / 3}-h
$$

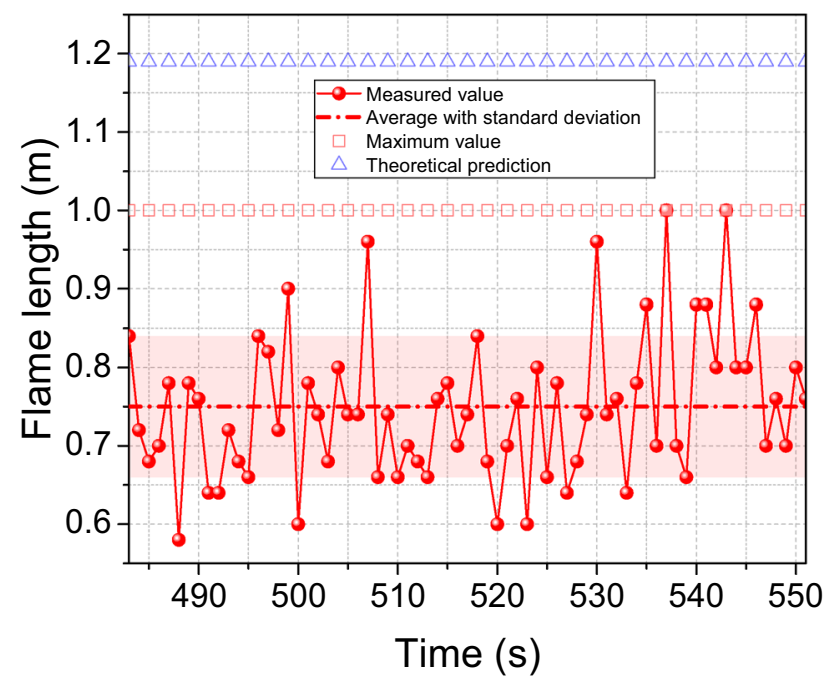

Figure 5. The flame length in study region. 


$$
\begin{aligned}
& h=\frac{A_{w} h_{w}+A_{d} h_{d}}{A_{w}+A_{d}} \\
& w=w_{w}+w_{d}
\end{aligned}
$$

where $h$ and $w$ are height and width of opening, respectively; subscript $d$ and $w$ represent the door and window; $R$ is the average rate of the burning, which is obtained from the experiment:

$$
R=\frac{M}{\tau}
$$

where $M$ is the mass of the burnt wood fuel in the experiment and $\tau$ is the burning time, which are $162 \mathrm{~kg}$ and $1171 \mathrm{~s}$, respectively. The door dimensions are $2.0 \times 0.8 \mathrm{~m}^{2}$ and the window dimensions are $0.6 \times 1.2 \mathrm{~m}^{2}$. Thus the flame height $(z)$ is calculated as $0.6 \mathrm{~m}$, and therefore $2 z / 3=0.4 \mathrm{~m}$, which happens to be the same height of the wall above the window/door of $0.4 \mathrm{~m}$, and is therefore on the borderline to determine if there is a wall or no wall above the opening in the model [25]. As in experiments, the ejected flame did not attach to the wall, so it is assumed to be identical to the condition of no-wall above the opening. Therefore, the horizontal length, $L(\mathrm{~m})$, along the centreline (axis) of the flame from the door is [25]:

$$
L=0.6 h\left(\frac{z}{h}\right)^{1 / 3}+h / 3
$$

The horizontal length, $L$, is theoretically calculated as $1.19 \mathrm{~m}$, which is slightly larger than the maximum flame length measured in the experiment, as plotted in Fig. 5.

In an open space, from a relatively large pool fire, radiation, rather than convection, normally dominates more than $90 \%$ the heat transfer between the fire and vertical panel [28]. From a recent outdoor tent experiment, the radiation seems to decay exponentially [18]. Thus, in this work, the radiation decay from the ejected flame tip to the possible combustible materials is assumed as an exponential equation. It should be noted that this is empirical correlation rather than a radiation calculation from view factors. To obtain relatively conservative results, the location of heat flux near to the flame tip is assumed to be $1.0 \mathrm{~m}$ which is the largest flame length in the study region. By fitting all the heat flux values in the study region, the function of radiative heat flux with distance is:

$$
I=4.26+123.8 e^{-1.3589 x}
$$

which is plotted in Fig. 6. It should be noted that within $1 \mathrm{~m}$ the heat flux is assumed constant and can ignite any combustible material immersed in the flame. 


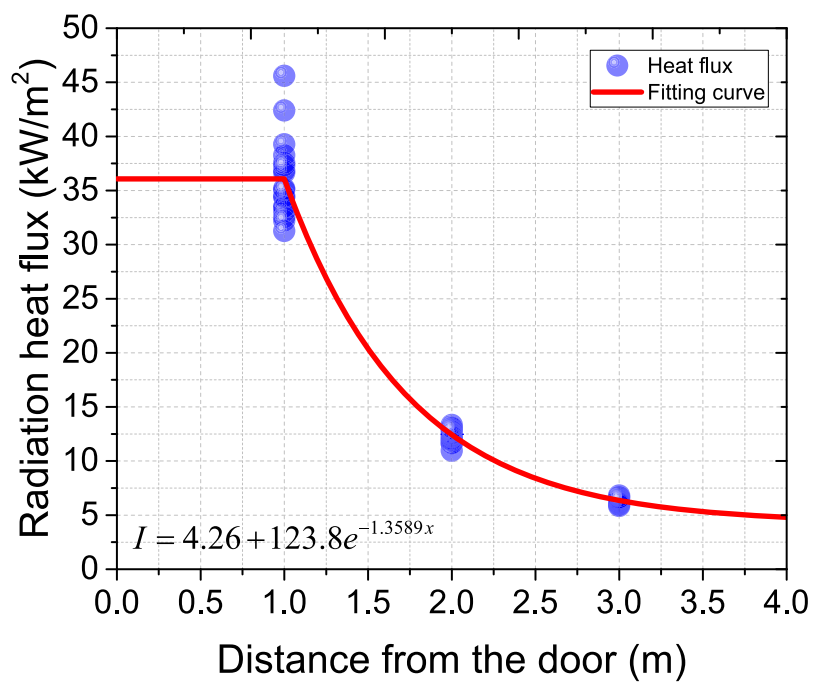

\section{Figure 6. The fitting of the radiation decay along the distance from the door.}

The CHFs of the materials in informal settlement measured by cone calorimeter are listed in Table 2 in descending order. Based on the Eq. (8), the critical distance, beyond which the material will not be ignited in an informal settlement fire, are obtained. The CHF lower limit is used for calculating a conservative result. The focus is the flame spread between dwellings, thus structural wood wall, lining cardboard, hanging clothing and curtain outside, tyre (always on the roof) and plastic netting are discussed. It is found that the critical distance of structural timer (No. 1) and cardboard (No. 10 and 11), normally used for wall construction and lining, is $2.14 \mathrm{~m}$, which suggests that wood dwellings should be built at least $2.14 \mathrm{~m}$ away from other dwellings to reduce the risk the wall or lining will not be ignited. Hanging clothing (No. 29-32) has a critical distance around $1.62 \mathrm{~m}$ to $2.14 \mathrm{~m}$, but it should be noted that clothing is often hung out to dry between dwellings. Meanwhile, shade netting (No. 8) and tyre (No. 9) are much easier to ignite with critical distances of $2.4 \mathrm{~m}$ and $2.8 \mathrm{~m}$, implying these plastic or rubber materials should be placed far away from the dwellings if possible. The PU foam, which is normally used as mattresses in an informal settlement, is the easiest material to be ignited with a critical distance of $3.14 \mathrm{~m}$. However, as it is always placed inside the room, so both the distance between the PU foam and fire would be larger than that between dwellings and there would be a large shielding affect from the walls which will decrease the probability of ignition. More information about these combustible materials and how they might contribute to the fire development and spread can be found in [4]. In addition, to make these risk assessments more specific, the type, layout and amount of the combustible materials in informal settlement should be investigated, which can be obtained from our survey data (analysis in process). However, the combustible material database is 


\section{Table 2}

The Critical Heat Flux of Materials and the Estimated Critical Distances

\begin{tabular}{|c|c|c|c|}
\hline No. & Material & Critical heat flux $\left(\mathrm{kW} / \mathrm{m}^{2}\right)$ [4] & Required critical distance $(\mathrm{m})$ \\
\hline 18 & Big green insulation (bed/sofa) & 38 to 39 & 1.00 \\
\hline 27 & Yellow smooth window curtain & 35 to 36 & 1.03 \\
\hline 17 & White polystyrene foam & 28 to 30 & 1.22 \\
\hline 21 & Pillow cover & 25 to 27 & 1.31 \\
\hline 13 & Advertisement & 25 to 26 & 1.31 \\
\hline 28 & Pink curtain & 25 to 26 & 1.31 \\
\hline 20 & Pink blanket & 23 to 24 & 1.39 \\
\hline 6 & Plastic bag & 22 to 23 & 1.43 \\
\hline 26 & Shower curtain & 22 to 23 & 1.43 \\
\hline 12 & Normal paper & 19 to 20 & 1.57 \\
\hline 2 & Fuel timber & 18 to 20 & 1.62 \\
\hline 4 & Timber furniture 1 & 18 to 19 & 1.62 \\
\hline 5 & Timber furniture 2 & 18 to 19 & 1.62 \\
\hline 30 & Black trousers & 18 to 19 & 1.62 \\
\hline 16 & Pink foam & 17 to 18 & 1.67 \\
\hline 29 & Blue T-shirt & 14 to 15 & 1.87 \\
\hline 22 & Red welcome carpet & 12 to 13 & 2.04 \\
\hline 32 & Women leggings & 12 to 13 & 2.04 \\
\hline 3 & Masonite timber & 11 to 12 & 2.14 \\
\hline 10 & Cardboard 1 & 11 to 12 & 2.14 \\
\hline 11 & Cardboard 2 & 11 to 12 & 2.14 \\
\hline 25 & Vinyl & 11 to 12 & 2.14 \\
\hline 31 & Grey trousers & 11 to 12 & 2.14 \\
\hline 1 & Structure timber & 11 to 12 & 2.14 \\
\hline 7 & Clear plastic sheet & 10 to 11 & 2.26 \\
\hline 8 & Shade netting & 9 to 10 & 2.40 \\
\hline 15 & Light yellow foam & 8 to 9 & 2.58 \\
\hline 19 & Colourful blanket & 8 to 9 & 2.58 \\
\hline 9 & Tyre & 7 to 8 & 2.80 \\
\hline 23 & Green carpet & 7 to 8 & 2.80 \\
\hline 24 & Yellow carpet & 7 to 8 & 2.80 \\
\hline 14 & Dark yellow foam & 6 to 7 & 3.14 \\
\hline
\end{tabular}

considered extensive enough to evaluate the critical separation distance in this work.

Therefore, from Table 2, it can be concluded that if all the materials are $3.14 \mathrm{~m}$ away, the risk of fire spread for the adjacent dwelling would be negligible. However, due to the competition for habitable space from residents, a more realistic and practicable minimum safe distance could be $2.14 \mathrm{~m}$ which could avoid ignition of $75 \%$ of the combustible materials listed, particularly the combustible wall and lining of adjacent dwelling. It should be noted that the experimental and theoretical results are based on laboratory conditions and need further verification with consideration of the complexity of informal settlement. Therefore, the technology of geographic information system is employed to analyse the real informal fires in the past years to ensure the accuracy of the separation distance. 


\section{Analysis of GIS}

\subsection{Methods}

Geographic information system analysis is employed to investigate the separation distance which, in reality, were effective in helping prevent fire spread and to determine the effective safe distance. In the case of urban fire, a combination of materials, separation distance, wind and suppression are all factors for fire spread. However, it can be found from the historical informal settlement fires that the burnt areas always ceased at some specific locations, such as road and canal. Thus, separation distances in the informal settlement played a very important role in fire spread even though dwelling dimension, construction materials and suppression varied significantly. High-resolution aerial photography is captured annually by the City of Cape Town in December and January from which the footprints of dwellings can be obtained. Four real fires were selected and the photographs available immediately prior to the fire were used to assess the separation distance between dwellings, for example, for the fire on 23 May 2014, the December 2013 aerial photograph was used and for the other 3 fires in 2015, the January 2015 aerial photograph was used. The extent of each fire was established using the historic viewer in Google Earth. The outlines of dwellings affected by fire were digitized from the corresponding aerial photograph at a scale of 1:200 using ArcGIS 10.5 software. Where it was not possible to distinguish a roof boundary or where roofs were too close together to be delineated by individual lines (at the scale of digitizing and image resolution this is approximately $15 \mathrm{~cm}$ ), dwellings were mapped as single dwellings. To extract information on the distance between dwellings which did ignite, the nearest distance between dwellings within the fire extent (i.e. all dwellings which burned) was calculated using the proximity tool 'NEAR' in ArcToolbox. Figure 7 shows the fire extent areas and corresponding dwelling footprints which were used for this analysis. It should be noted that using this method, construction material, dwelling design, fuel load, and size and location of doors and windows, are lumped into a single parameter i.e. distance at which fire did or did not spread. Thus, findings are specific to settlements of similar nature to the one considered. Should this method be applied to other cities, fire spread distances from historic fires would need to be obtained from aerial photography using the method detailed here.

For information on the distance across which fire did not spread, a fire line was created using the outermost extent of the dwellings affected by fire and points were placed along each fire line at an equal interval. Similarly, an unburned dwelling line (UDL) on the opposite side of the road/canal was digitized, as shown in Fig. 8. The nearest distance from each of these created points to the UDL was calculated using the Proximity tool 'NEAR' in ArcToolbox.

The method proposed in [29] is used in this work to determine the high-risk area for fire spread as well as the probable fire pathway, as illustrated in Fig. 9. Since dwellings are digitized from aerial photography of $6 \mathrm{~cm}$ to $8 \mathrm{~cm}$ resolution, values are rounded off to the nearest $10 \mathrm{~cm}$. The precision cannot be improved given the precision of the input data. In addition, the dwelling footprint layer is captured at a scale of 1:200 in ArcGIS from the City of Cape Town aerial pho- 

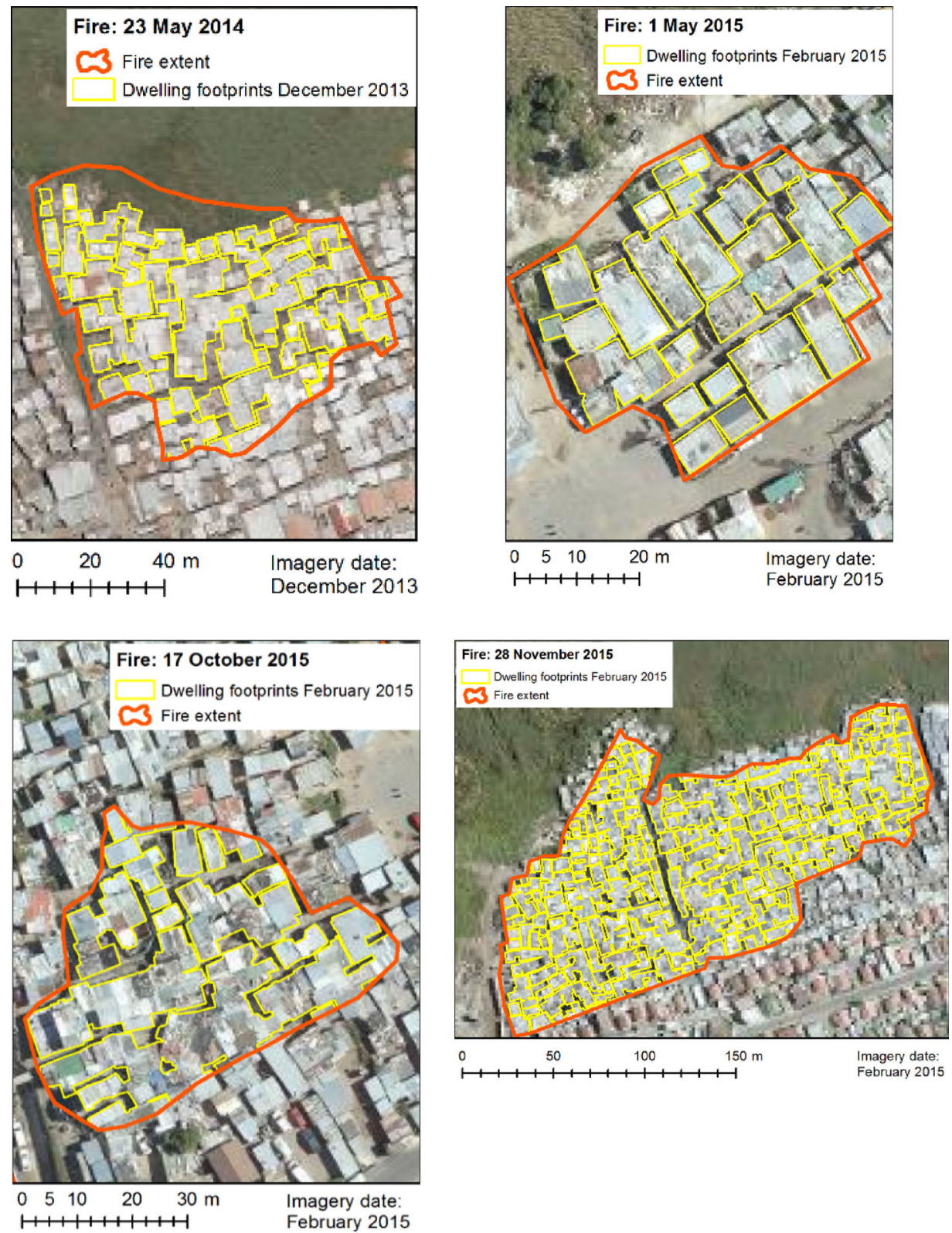

\section{Figure 7. The burn scar for fire-spread distance measures.}

tography. The dwelling footprint layer is then buffered by half of the chosen probability distance. For example, if a $95 \%$ probability of fire spread is given as $1 \mathrm{~m}$, the footprint layer is buffered by $0.5 \mathrm{~m}$. Thus, dwellings within $100 \%$ of chosen probability distance are joined in the same buffer polygon (probability buffer in 

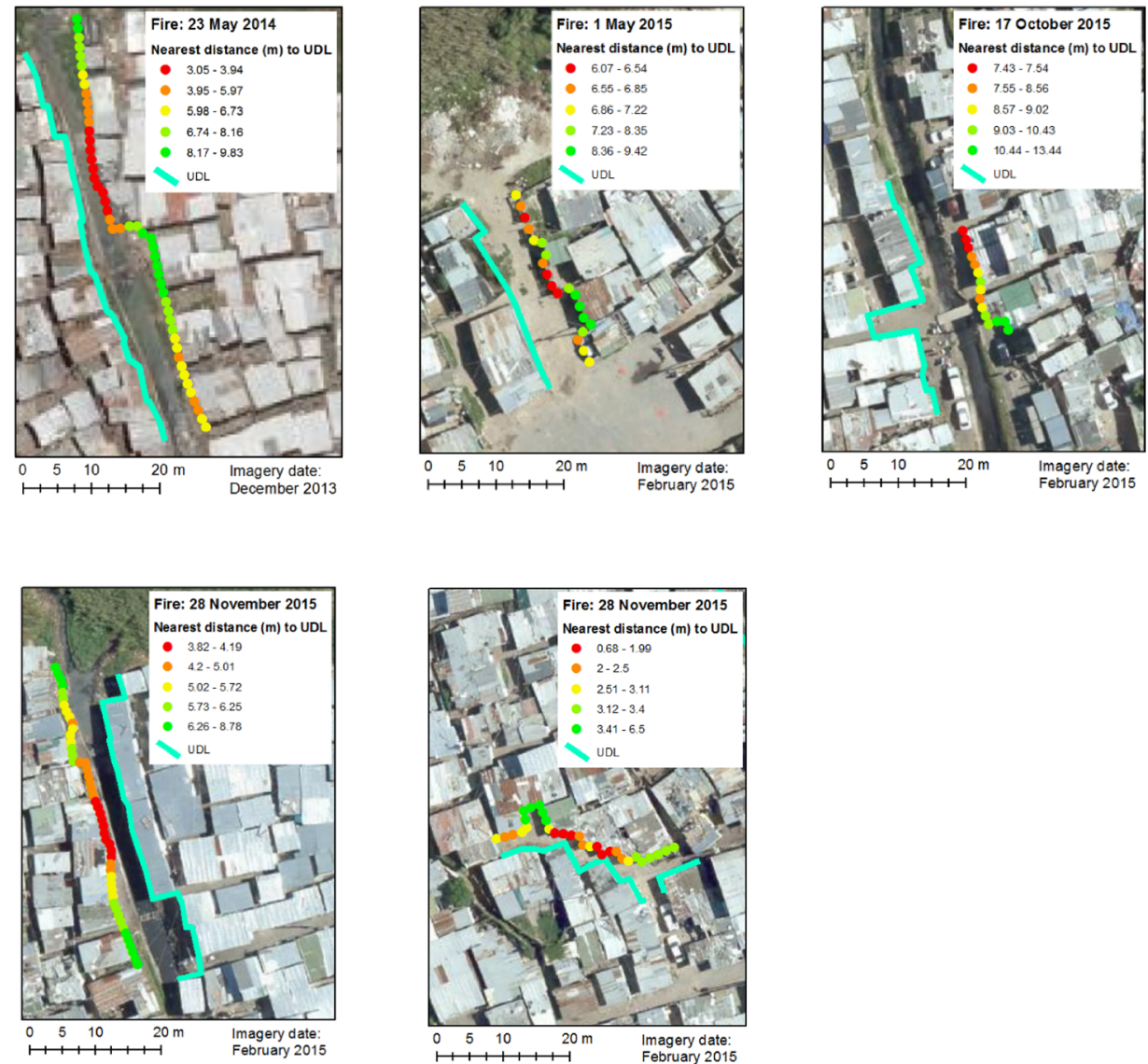

\section{Figure 8. The analysis region where the fire did not spread.}

Fig. 9b). The probability buffer is in turn negatively buffered by the same distance ( $0.5 \mathrm{~m}$ in the example given) to create a layer containing the dwelling footprints as well as the possible fire spread pathways. Therefore, this layer provides an indication of where within a settlement, or a group of dwellings fire spread is likely to occur. Effects of construction materials, window size and locations are not considered as we do not have this level of detail in data. Analysis of fire spread from real fires did not consider the location of openings, the potential fire pathways did not consider this either and fire spread from and to dwellings is assumed to not be dependent on the location of openings. The data obtained are analyzed in the following section.

\subsection{Results}

From the four fires analysis in GIS, a total of 257 fire-spread and 227 fire-notspread distances are obtained. The function of Weibull distribution is used to summarize the distances where the fire did and did not spread. Due to the uncer- 


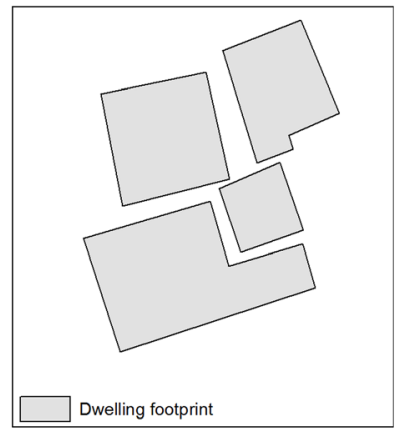

(a)

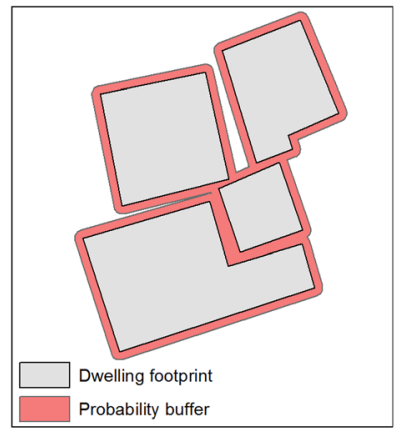

(b)

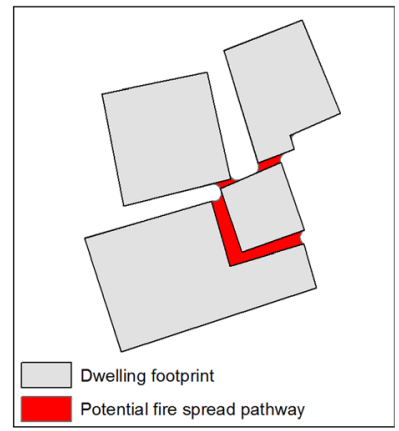

(c)

Figure 9. Illustration of method used to calculate potential fire spread pathways. (a) Dwelling footprints are digitized; (b) dwelling footprints are buffered by the chosen distance for the probability buffer; (c) the probability buffer is in turn buffered by negative the probability buffer distance to leave polygons indicating potential fire spread pathways.

tainties of fire spread, a probabilistic rather than a deterministic approach is employed to determine the critical distance in the fire. The cumulative Weibull function is employed to describe the distribution of the measured parameters. The three-parameter Weibull function is [30]:

$$
F(\mathrm{x})=1-\exp \left[-\left(\frac{x-\gamma}{\eta}\right)^{\beta}\right] \quad x \geq \gamma
$$

with $\eta, \beta$ and $\gamma$ being the scale, shape and location parameters, respectively. If $\gamma=0$, the distribution becomes the two-parameter Weibull distribution. The survival probability of a dwelling is determined according to the measured results and is the general form of the cumulative Weibull distribution function. In this work, the survival probability increases from 0 to 1 when the distance between dwellings increases. It should be noted that the survival probability is a statistical concept rather the residents' lives survival probability. The results are shown in Fig. 10 with corresponding functions in which the $\mathrm{R}^{2}$ are both 0.99 . These figures clearly present the data distribution and show a very good fit.

What is important is to be able to get the fire spread probability at a given distance, however, if, for instance, a 0.95 survival probability is required, the two curves in Fig. 10 give very different results: $0.68 \mathrm{~m}$ from the curve of fire spread and $9.68 \mathrm{~m}$ from not fire spread curve. Therefore, a statistical method needs to be proposed to combine the two sets of data. From the data, it can be found that a significant characteristic is the overlap of fire spread and non-spread cases. For example, from the GIS data for fire spread distance, it was found the fire may spread at $2 \mathrm{~m}$ in some case; for the no-fire spread analysis, it was found the fire may not spread at $2 \mathrm{~m}$ distance. This overlap primarily occurs at around $1 \mathrm{~m}$ to 


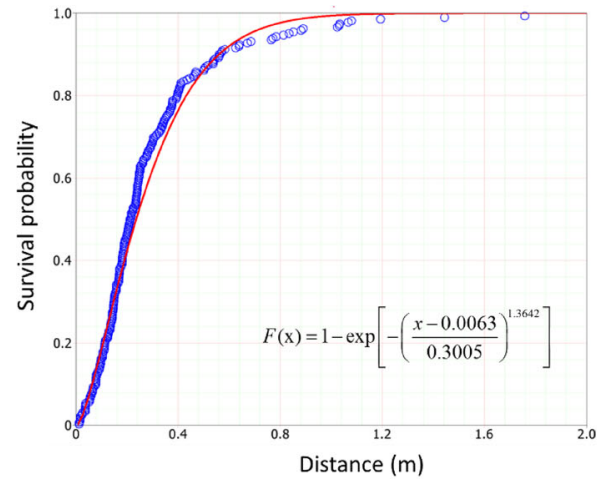

(a) The survival probability obtained from fire-spread distances

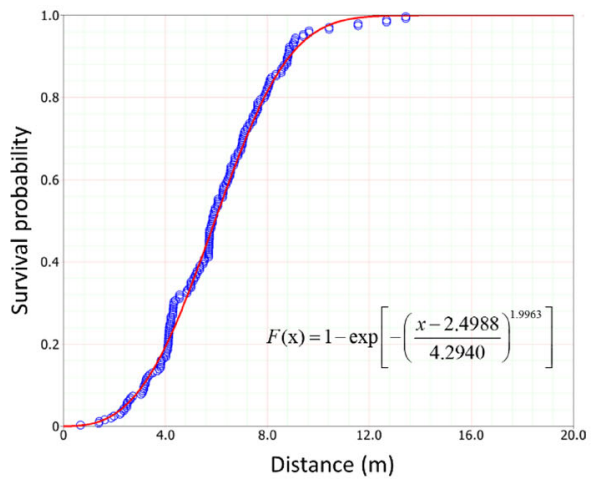

(b) The survival probability obtained from fire-not-spread distances

\section{Figure 10. The dafa summary using Weibull distribution. (a) The survival probability obłained from fire-spread distances. (b) The survival probability obtained from fire-not-spread distances.}

$2 \mathrm{~m}$. The nature of fire spread in this work is ignition by radiation, which only has two consequences that are similar to the hot surface ignition issue [31]. Instead of a sharp demarcation point indicative of a well-defined fire spread critical distance, there is a broad range of distances at which the fire spread is more likely. To present a meaningful interpretation, a logistic regression curve fit of all the data is employed [32]:

$$
p(D)=\frac{\exp (a+b D)}{1+\exp (a+b \mathrm{D})}
$$

where $D$ is the distance; $a$ and $b$ are the coefficients to be determined. By fitting the data, the function is:

$$
\text { No-spread Probability }=\frac{\exp (-6.927+4.310 D)}{1+\exp (-6.927+4.310 D)}
$$

which is plotted in Fig. 11. It can be seen that the overlap is primarily in the range of $0.68 \mathrm{~m}$ to $2.31 \mathrm{~m}$, while the refined range will be $1.40 \mathrm{~m}$ to $2.31 \mathrm{~m}$ if the minimum value of 0.68 of no-spread distance is excluded as it is significantly smaller than other data, which suggest that in this range the fire may spread or not spread within this distance. Table 3 lists the survival probability corresponding to each distance. It can be found that at $2.29 \mathrm{~m}$ with lower bound $1.94 \mathrm{~m}$ and upper bound $2.98 \mathrm{~m}$ there is a $95 \%$ probability that fire will not spread, while $5.0 \mathrm{~m}$ is required if the probability of no fire spread is to be essentially $100 \%$.

Based on the results from 2014 and 2015 in above analysis, the survival probability equation is applied to the January 2018 dwelling footprints for Masi- 


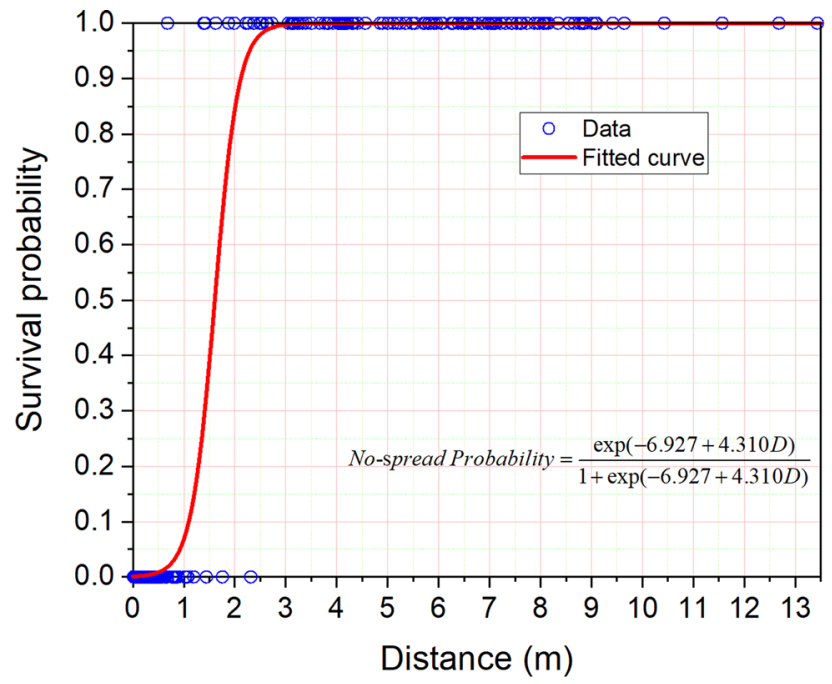

Figure 11. The probability of fire spread with a function of the separation distance between dwellings.

\section{Table 3}

The Corresponding Distances at Different Survival Probability

\begin{tabular}{llll}
\hline Probability & $\mathrm{D}(\mathrm{m})$ & Lower bound $95 \%$ & Upper bound $95 \%$ \\
\hline 0.01 & 0.541 & 0.020 & 0.834 \\
0.05 & 0.924 & 0.569 & 1.174 \\
0.10 & 1.097 & 0.797 & 1.348 \\
0.20 & 1.286 & 1.023 & 1.558 \\
0.30 & 1.411 & 1.160 & 1.712 \\
0.40 & 1.513 & 1.265 & 1.845 \\
0.50 & 1.607 & 1.356 & 1.972 \\
0.60 & 1.701 & 1.443 & 2.103 \\
0.70 & 1.804 & 1.535 & 2.250 \\
0.80 & 1.929 & 1.642 & 2.433 \\
0.90 & 2.117 & 1.797 & 2.714 \\
0.95 & 2.290 & 1.935 & 2.978 \\
0.99 & 2.673 & 2.233 & 3.570 \\
\hline
\end{tabular}

Figure 12. Fire spread probability function applied to Masiphumelele 2018 to determine (a) 5\%, (b) 50\% and (c) $95 \%$ fire spread possibility. The different colours represent individual fire spread blocks, i.e. at the displayed fire spread probability level, the fire will not spread between blocks of different colours. 


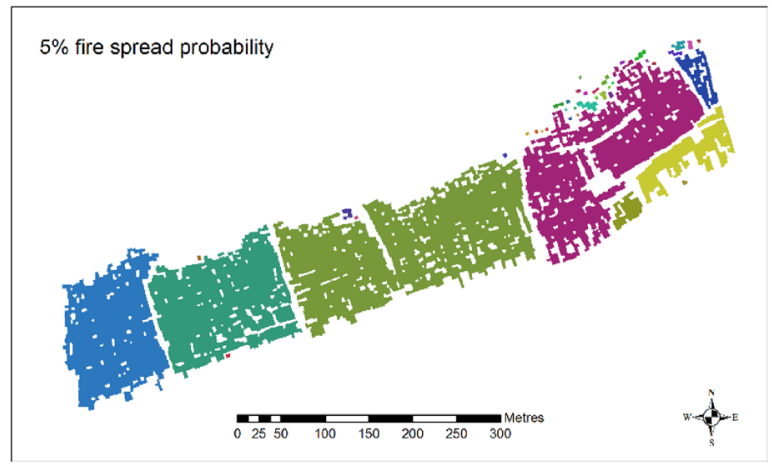

(a)

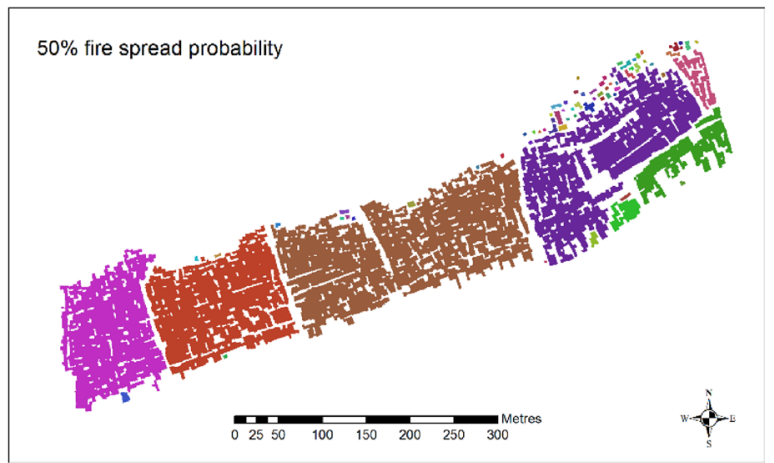

(b)

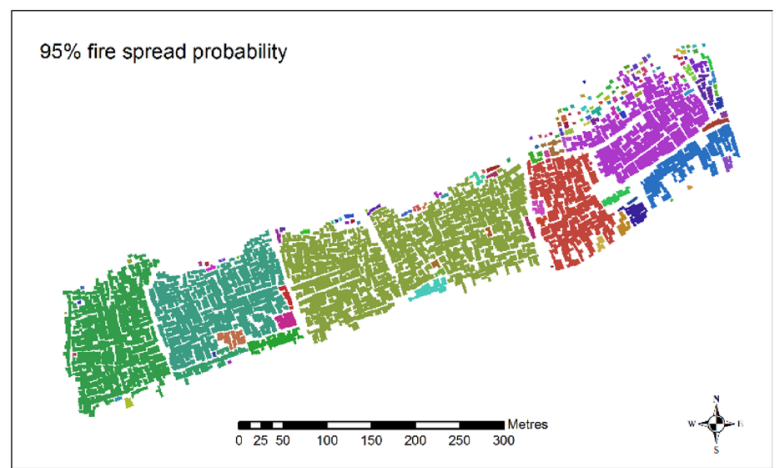

(c) 
phumelele to determine the fire spread vulnerability of the settlement in its current layout. The 95,50 and $5 \%$ probabilities of fire spread $(5 \%, 50 \%$ and $95 \%$ survival probabilities) in Masiphumelele are displayed in Fig. 12. In these figures, each individual colour demarcates a fire spread block at the indicated level of probability. In interpreting these figures, it should be noted when working with the higher probability of spread a smaller burn area will result than when working with a lower probability of spread. This is because the probability of spread is inversely related to the distance between dwellings in that the closer together dwellings are, then the more likely fire is to spread. However, this is dependent on the layout and the interconnectivity of probability buffers, as illustrated in Fig. 9. Thus at $5 \%$ fire spread probability, it can be seen that the settlement is broadly divided into four major blocks and these blocks largely persist at $50 \%$ and $95 \%$ although at $95 \%$ probability, the most easterly block is divided into two separate blocks. This shows the post-fire rebuilding has reduced the fire spread probability in the portion of the settlement destroyed by the fire in November 2015 (Fig. 1) as the gap between the two most westerly blocks is sufficient to prevent fire spread. Despite this, the result indicates that Masiphumelele remains highly susceptible to large devastating fires. Although there are serendipitous "fire safety separation" in place in the form of canals, at the southernmost end of the most westerly canal, dwellings are within high fire spread proximity of each other, enabling fire to spread despite these breaks being in place.

As a potential small intervention which can be put in place to dramatically increase the fire spread safety of the community, the third most westerly block displayed in olive green, as shown in Fig. 12c, is analyzed in detail. When considering the $95 \%$ probability of spread, it can be seen that the settlement on either side of the canal is joined by a fire spread pathway at one dwelling, indicated by a green circle in Fig. 13. Furthermore, from aerial photography, it appears that this may be an add-on extension to an existing dwelling. The removal of this extension will effectively separate the eastern and western portion of this block reducing the risk of both sides of the block being destroyed in a single fire. Should the removal of this extension not be possible, the fire department should be alerted to this location as a high-risk point and targeted suppression intervention can take place at this location.

\section{Comparison and Discussion}

\subsection{Comparison}

Effective separation distances could be a practical and effective method to improve the resilience of informal settlements to fire. Fire safety experiments and GIS statistical analysis were used to evaluate the required distances to ensure the fire safety of informal settlements. From the full-scale laboratory experiments, it was found that a distance of $2.14 \mathrm{~m}$ might be good enough to avoid ignition of more than $75 \%$ of materials commonly found in informal settlements, in particular, the ignition of the timber wall on adjacent dwellings is unlikely to occur at this distance. However, due to hanging plastic shading or tyres on the roof with very low 


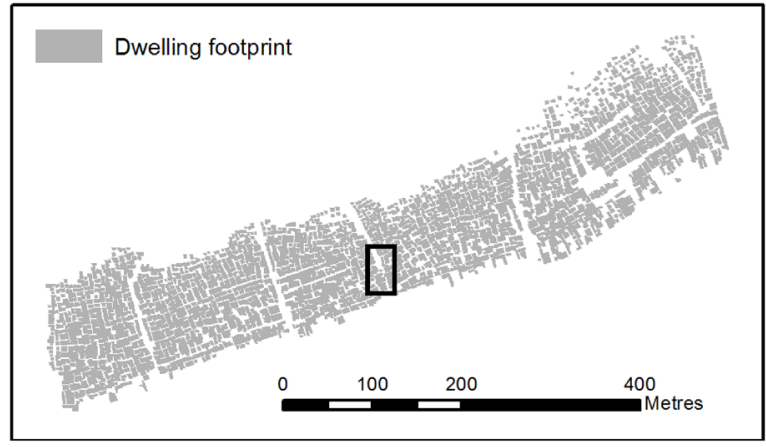

(a)

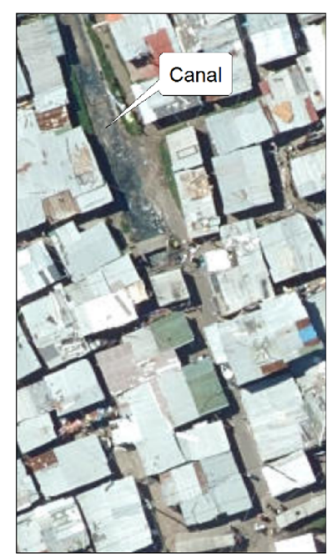

(b)

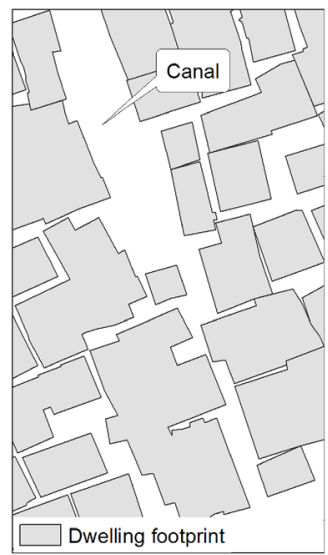

(c)

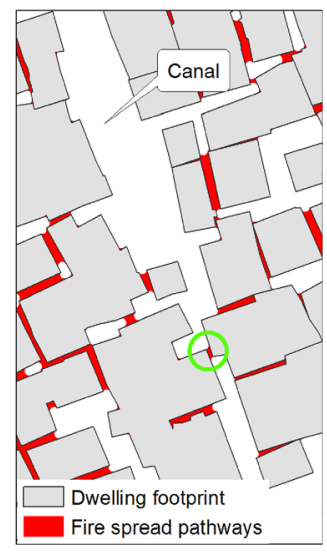

(d)

Figure 13. (a) Extent rectangle showing location of maps b, c, and d; (b) February 2018 aerial photography; (c) digitized dwelling footprints from February 2018 aerial photography; (d) $95 \%$ fire spread pathways with point of probably fire spread between eastern and western portion of the block indicated by the green circle.

$\mathrm{CHF}$, the safety distance should be at least $2.80 \mathrm{~m}$, beyond which $97 \%$ of materials would be unlikely to ignite. The adjacent dwelling, from the analysis of laboratory experiments, seems to have zero chance of ignition if distances are increased above $3.14 \mathrm{~m}$. The relationship between the distance and the survival possibility is presented in Fig. 14, in which the cumulative distribution function from experiments is calculated by:

$$
p(\mathrm{X} \leq x)=1-\frac{N_{\text {ignited }}(x)}{N_{\text {total }}}
$$




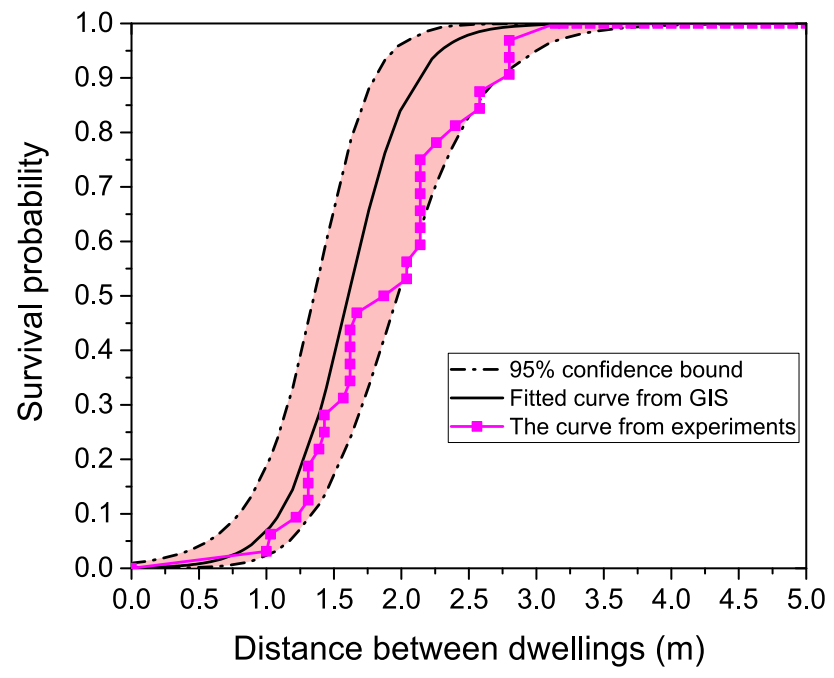

\section{Figure 14. The cumulative function of survival probability from experiments and GIS.}

where $N_{\text {ignited }}(x)$ is the number of ignited items within the distance $x ; N_{\text {total }}$ is the total number of the materials that is 32 in this work. It can be seen that the curve from experiments fits very well with the curve from GIS analysis when the distance is smaller than $1.6 \mathrm{~m}$, but slight difference occurs when the distance increases. In real fires, besides manual intervention and fire supressions, the effect of wind (even small ones) can explain the shift from the experimental curve to the GIS curve, which implicitly includes the influence of wind at the time of the fires analysed. This is supported by another series of experiments conducted in South Africa, where it was found that wind may both accelerate or slow down the fire spread rate [33] depending on its orientation to dwellings and their separation distances. The experimental curve still falls well within $95 \%$ confidence bound, which suggests that both methods give reasonable and reliable results.

The survival probability does not imply the survival of the entire settlements or that no lives will be lost, but rather represents the fire spread between a dwelling and its adjacent dwelling(s). Although each method has its own assumptions and limitations, their results are in good agreement and could be used to provide a valuable reference for the fire safety design of informal settlement planning. It would be difficult to make all the dwellings have a distance as large as those suggested due to the competition for habitable space by residents in informal settlements, but it could be a promising option to divide the whole area into several blocks by canals, roadways, or fireproof wall as "fire compartmentalization". In addition, due to the nature of informal settlement development, firefighting systems in these residential areas are very limited, and the applicability of smoke detectors is still to be fully verified [34]. During the firefighting operations, residents have been known to inhibit the strategic efforts of the fire service to address 
their immediate concern of protecting their own dwelling [6]. Thus, a permanent method to promote fire safety, i.e. the separation distances, would be a useful way to avoid the fire spread.

It should be noted that in this work, the fire spread by firebrands is not considered for the estimation of critical distance as fire can spread via this mechanism by as much as a few kilometres in a real wildland-urban interface (WUI) areas $[35,36]$ however there is no evidence to date of fire brands being a mechanism for fire spread in informal settlements.

To provide a reliable distance, the summary of the distances with $5 \%, 10 \%$, $50 \%, 90 \%, 95 \%$ and $100 \%$ from the two methods are listed in Table 4 . It can be found that the GIS results with $95 \%$ upper bound are very similar to the results from experiments, which can give relatively conservative results. Both of them show that $1 \mathrm{~m}$ has only $2 \%$ to $3 \%$ safety probability, while $2 \mathrm{~m}$ has a $52 \%$ safe distance, which is very consistent with the authors' 12 -dwelling experiments, in which, all the dwelling with $1 \mathrm{~m}$ from adjacent burning dwelling were ignited and when the distance is $2.0 \mathrm{~m}$, one spread occurred and two did not. Therefore, to achieve the $95 \%$ no fire spread separation distance, $2.80 \mathrm{~m}$ to $2.98 \mathrm{~m}$ is required, thus to be conservative, $3.0 \mathrm{~m}$ as a minimum is recommended from this work, which can be used for reblocking and redesign of the informal settlement.

\subsection{Validation}

To validate if the method can be used to predict fire extents in a settlement, the informal settlement of Kosovo, Cape town, South Africa is selected. Kosovo has experienced at least six large devastating fires since 2016. Although it has a high dwelling density, there are roads of varying widths and degree of formality which demarcate the settlement into clear blocks. This combination of high settlement density and differing width of gaps between the settlement blocks lends Kosovo to be an ideal settlement example to test the ability of the method of fire spread extent. A distance of $1 \mathrm{~m}$ with $2 \%$ to $3 \%$ survival ( $97 \%$ to $98 \%$ fire spread) probability is used. The method illustrated in Fig. 9 is employed with a buffer of $0.5 \mathrm{~m}$ (equivalent to the critical separation distance of $1 \mathrm{~m}$ ). The prediction of fire scars

\section{Table 4}

The Comparison of the Corresponding Probability from Two Different Methods

\begin{tabular}{lllll}
\hline & \multicolumn{3}{c}{ Distances from GIS (m) } & \\
\cline { 2 - 4 } Survival probability (\%) & $95 \%$ lower & D (m) & $95 \%$ upper & Distances from experiments (m) \\
\hline 5 & 0.57 & 0.92 & 1.17 & 1.02 \\
10 & 0.80 & 1.10 & 1.35 & 1.24 \\
50 & 1.36 & 1.61 & 1.97 & 1.87 \\
90 & 1.80 & 2.12 & 2.71 & 2.76 \\
95 & 1.94 & 2.29 & 2.98 & 2.80 \\
100 & 3.68 & 4.56 & 6.39 & 3.14 \\
\hline
\end{tabular}




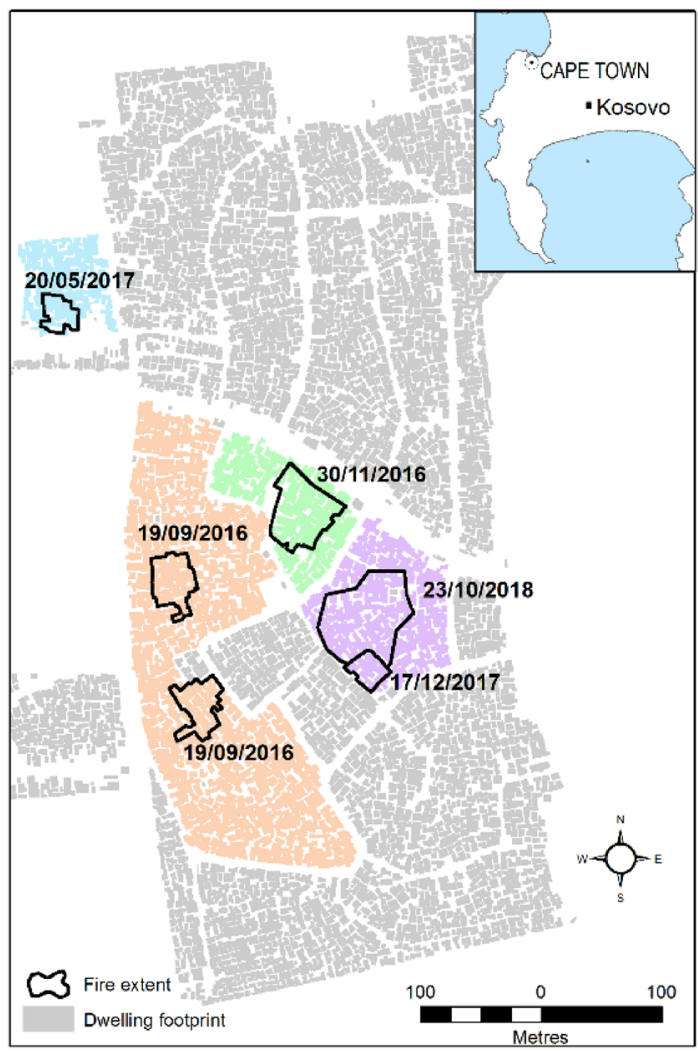

\section{Figure 15. Location of Kosovo informal settlement showing fire extents and their approximate dates and predicted fire extents using a $1 \mathrm{~m}$ critical separation distance for the settlement of Kosovo. Colours represent individual predicted fire spread events.}

is shown in Fig. 15. It is found that the extent of each fire is overestimated but this is expected since the method assumes the complete absence of fire suppression activity from firefighters or residents and no wind effect is considered. Additionally, it should be noted that as the 95\% upper bound in Fig. 14 is used, which is most conservative, thus it is reasonable that the predicted areas are larger than the real burnt scar. However, it can be established that notably the gaps between blocks are sufficiently wide to prevent fire spread between blocks in the case of the fires of 30/11/2016, 20/05/2017, 17/12/2017 and 23/10/2018.

The two fires of September 2016 were contained to a small area relative to the size of the predicted fire extent (peach colour in Fig. 15). It is assumed that quick response fire suppression limited the fires in these two cases however, this block of the settlement is at particular risk of large fires due to the layout of the dwellings. As was shown in the Masiphumelele example, relatively minor interventions may be possible within this block to reduce the size of the predicted (and assumed actual) fires. Similarly, residents living in the pale green block (Fig. 15) could ben- 
efit from minor interventions to divide the block into two at the northwestern extent of the 30/11/2016 fire extent.

Overall, the prediction of the burning area from GIS is conservative, so it can be employed in the future fire risk mapping of the informal dwellings with a distance of $1.0 \mathrm{~m}$. However, it should be noted that this prediction does not consider the factors of firefighters or residents' intervention and the possible wind effect.

\section{Conclusions}

In this work, to determine the safe fire separation distance in an informal settlement, two parallel methods were used: experiments and GIS methods. From the full-scale experiments and a simple theoretical model, the radiation heat fluxes were measured and calculated to present a decay curve that varies with the distance between dwellings. The ignition probability is determined from the critical heat fluxes of 32 combustible materials obtained from cone calorimeter tests. From GIS, around 500 distances were measured in four real fires and statistical analyses, namely Weibull and logistic regression, were performed. Instead of the deterministic analysis, both methods demonstrate probabilistic results which agree well with each other. The primary conclusions are as follows:

1. With the experimental condition in this work, the maximum horizontal flame length from the door is around $1.0 \mathrm{~m}$, and from $1 \mathrm{~m}$ to $4 \mathrm{~m}$ from the dwelling, the radiation heat flux decreases from $36 \mathrm{~kW} / \mathrm{m}^{2}$ to $5 \mathrm{~kW} / \mathrm{m}^{2}$.

2. Combining the full-scale laboratory experiments with cone calorimeter results on common materials found in informal settlements, it was established that a distance of $3.14 \mathrm{~m}$ could potentially avoid most possible ignitions of the materials outside the dwellings.

3. From the GIS analysis of Masiphumelele fires, it was found through logistic regression analyses that a $2.29 \mathrm{~m}$ separation distance between dwellings would provide a $95 \%$ survival probability during a fire, while $4.56 \mathrm{~m}$ could provide a nearly $100 \%$ fire safe distance. Due to the diversity of informal settlements globally, careful consideration is needed as to whether these results are applicable to the specific context, however these data can provide a good reference for other locations. For more universal applications, more research is needed considering a wider range of informal settlement layouts and constructions.

4. The experimental separation distance results agree well with the GIS analyses with $95 \%$ confidence bound. In particular, the results in the upper $95 \%$ bound are almost identical to the experiments, which can thus be considered as conservative results.

5. Through a comparison between the two methods in this work and real-scale 12-dwelling experiments, the probability of the adjacent dwelling being ignited is $97 \%$ to $98 \%$ when the distance between them is $1.0 \mathrm{~m}$. Meanwhile, at $2.0 \mathrm{~m}$ the probability for ignition is almost $50 \%(52 \%)$, while at 3.0 meters the probability of ignition is $5 \%$. 
6. The separation distance of $1.0 \mathrm{~m}$ determined in this work can conservatively predict the fire scar in other informal settlements, and could be used in the future fire risk assessment of informal settlement.

\section{Acknowledgements}

The authors would like to acknowledge Mr Paul Menou and Arthur Morvan from the University of Angers in France for the help during the data analysis, This work is supported by IRIS-Fire project of UK (Engineering and Physical Sciences Research Council Grant no.: EP/P029582/1). Dr. Yu Wang is supported by University of Science and Technology of China Start Research Funding (KY2320000023). Aerial photography was obtained from the City of Cape Town via the Open Data portal (https://web1.capetown.gov.za/web1/opendataportal/Dat asetDetail? DatasetName $=$ Aerial $\% 20$ photography), however, the City of Cape Town does not warrant or guarantee the quality or accuracy of the data, accessed, extracted and/or used from this site.

\section{Open Access}

This article is licensed under a Creative Commons Attribution 4.0 International License, which permits use, sharing, adaptation, distribution and reproduction in any medium or format, as long as you give appropriate credit to the original author(s) and the source, provide a link to the Creative Commons licence, and indicate if changes were made. The images or other third party material in this article are included in the article's Creative Commons licence, unless indicated otherwise in a credit line to the material. If material is not included in the article's Creative Commons licence and your intended use is not permitted by statutory regulation or exceeds the permitted use, you will need to obtain permission directly from the copyright holder. To view a copy of this licence, visit http://creat ivecommons.org/licenses/by/4.0/.

\section{References}

1. Lemanski C, Oldfield S (2009) The parallel claims of gated communities and land invasions in a Southern city: polarised state responses. Environ Plan A 41:634-648

2. Habitat U (2013) State of the world's cities 2012/2013: prosperity of cities. Routledge, London

3. DMFRS (2015) Western Cape Strategic Framework for Fire and Burn Injury Prevention. Western Cape Disaster Management and Fire Rescue Services

4. Wang Y, Bertrand C, Beshir M, Kahanji C, Walls R, Rush D (2020) Developing an experimental database of burning characteristics of combustible informal dwelling materials based on South African informal settlement investigation. Fire Saf J 111:102938

5. Habitat U (2015) Habitat III issue paper 22 -informal settlements. UN Habitat, New York 
6. Kahanji C, Walls RS, Cicione A (2019) Fire spread analysis for the 2017 Imizamo Yethu informal settlement conflagration in South Africa. Int J Disaster Risk Reduct 39:101146

7. Gibson L, Engelbrecht J, Rush D (2019) Detecting historic informal settlement fires with sentinel 1 and 2 satellite data-two case studies in Cape Town. Fire Saf $\mathbf{J}$ 108:102828

8. Walls R, Olivier G, Eksteen R (2017) Informal settlement fires in South Africa: fire engineering overview and full-scale tests on "shacks". Fire Saf J 91:997-1006

9. Beshir M, Wang Y, Gibson L, Welch S, Rush D (2019) A computational study on the effect of horizontal openings on fire dynamics within informal dwellings. In: Ninth international seminar on fire and explosions hazards, St Petersburg, Russia

10. Harte EW, Childs IR, Hastings PA (2009) Imizamo Yethu: a case study of community resilience to fire hazard in an informal settlement Cape Town, South Africa. Geogr Res 47:142-154

11. Barnett CJFSS (1989) Fire separation between external walls of buildings. Fire Saf Sci 2:841-850

12. McGuire J (1965) Fire and the spatial separation of buildings. Fire Technol 1:278-287

13. Atallah S, Allan DSJFT (1971) Safe separation distances from liquid fuel fires. Fire Technol 7:47-56

14. Zhang L, Yang S (2011) Determination of fire separation distance for CNG filling stations. Gas Heat 5

15. BRE (2014) BR187 - external fire spread, building separation and boundary distances, 2nd edn. BRE, Garston

16. Van Coile R, Maeso D (2017) Methodology for evaluating the safety level of current accepted design solutions for limiting fire spread between buildings. In: 14th International probabilistic workshop. Springer, Berlin, pp 485-497

17. Wang H, Li D, Ma R (2014) Experiment and computer simulation of fire safety distance between unlined relief tents. J Fire Sci Technol 6:18

18. Ma R (2013) Deciding the fire separation distance between color steel houses or relief tents based on fire experiment. J Fire Sci Technol 7

19. Wang Y, Gibson L, Beshir M, Rush D (2020) Preliminary investigation of critical separation distance between shacks in informal settlements fire. In: Wu G-Y, Tsai K-C, Chow WK (eds) The proceedings of 11th Asia-Oceania symposium on fire science and technology. Springer Singapore, Singapore, pp 379-389

20. Wang Y, Beshir M, Cicione A, Hadden R, Krajcovic M, Rush D (2020) A full-scale experimental study on single dwelling burning behavior of informal settlement. Fire Saf J 103076

21. Corner IR (1993) International Standard-fire tests-full-scale room test for surface products; ISO 9705: 1993. International Organisation for Standardisation, Geneva

22. Beshir M, Cicione A, Wang Y, Welch S, Rush D (2019) Re-visiting NIST reduced/fullscale enclosures (R/FSE). In: InterFlam, London

23. ISO (2002) Reaction-to-fire tests, heat release, smoke production, and mass loss rate- part 1: heat release rate (cone calorimeter method). ISO, Geneva

24. ASTM E1354 (2011) Standard test method for heat and visible smoke release rates for materials and products using an oxygen consumption calorimeter. American Society for Testing and Materials, West Conshohocken

25. Law M, O'Brien T (1981) Fire safety of bare external structural steel. Steel Construction Institute, Ascot

26. Lee SW, Davidson RA (2010) Physics-based simulation model of post-earthquake fire spread. J Earthq Eng 14:670-687 
27. Himoto K, Tanaka T (2008) Development and validation of a physics-based urban fire spread model. Fire Saf J 43:477-494

28. Wang Y, Wang Q, Su Y, Sun J, He L, Liew KM (2015) Fracture behavior of framing coated glass curtain walls under fire conditions. Fire Saf J 75:45-58

29. Stevens S (2019) Modelling the relative risks of large fires across the informal settlements of Cape Town. University of Edinburgh, Edinburgh

30. Weibull W (1951) A statistical distribution function of wide applicability. J Appl Mech Trans ASME 18:293-297

31. Colwell JD, Reza A (2005) Hot surface ignition of automotive and aviation fluids. Fire Technol 41:105-123

32. Hosmer DW Jr, Lemeshow S, Sturdivant RX (2013) Applied logistic regression. Wiley, New York

33. Wang Y, Beshir M, Gibson L, Stevens S, Bisby L, Rush D (2020) How "informal" is an informal settlement fire? SFPE Europe 2

34. Zweig P, Pharoah R, Eksteen R, Walls R (2018) Installation of smoke alarms in an informal settlement community in Cape Town, South Africa-final report. Western Cape Government Disaster Management

35. Koo E, Pagni PJ, Weise DR, Woycheese JP (2010) Firebrands and spotting ignition in large-scale fires. Int J Wildl Fire 19:818-843

36. Suzuki S, Manzello SL (2020) Garnering understanding into complex firebrand generation processes from large outdoor fires using simplistic laboratory-scale experimental methodologies. Fuel 267:117154

Publisher's Note Springer Nature remains neutral with regard to jurisdictional claims in published maps and institutional affiliations. 